OPEN ACCESS

Edited by:

Deepika Sharma,

University of Chicago, United States

Reviewed by:

Min Lu,

Icahn School of Medicine at Mount

Sinai, United States

*Correspondence:

Ramanjaneyulu Allam

allam.ramanjaneyulu@

dbmr.unibe.ch

tORCID:

Ramanjaneyulu Allam orcid.org/0000-0002-2789-3596

Specialty section:

This article was submitted to

Cell Death and Survival,

a section of the journal

Frontiers in Cell and Developmental

Biology

Received: 30 November 2021

Accepted: 21 December 2021

Published: 27 January 2022

Citation:

Andina N, Bonadies N and Allam R

(2022) Inflammasome Activation in

Myeloid Malignancies-Friend or Foe?

Front. Cell Dev. Biol. 9:825611.

doi: 10.3389/fcell.2021.825611

\section{Inflammasome Activation in Myeloid Malignancies-Friend or Foe?}

\author{
Nicola Andina ${ }^{1,2}$, Nicolas Bonadies ${ }^{1,2}$ and Ramanjaneyulu Allam ${ }^{1,2 * t}$ \\ ${ }^{1}$ Department of Hematology and Central Hematology Laboratory, Inselspital Bern University Hospital, University of Bern, Bern, \\ Switzerland, ${ }^{2}$ Department for BioMedical Research, University of Bern, Bern, Switzerland
}

Myeloid malignancies including myelodysplastic syndromes, myeloproliferative neoplasms and acute myeloid leukemia are heterogeneous disorders originating from mutated hematopoietic stem and progenitor cells (HSPCs). Genetically, they are very heterogeneous and characterized by uncontrolled proliferation and/or blockage of differentiation of abnormal HSPCs. Recent studies suggest the involvement of inflammasome activation in disease initiation and clonal progression. Inflammasomes are cytosolic innate immune sensors that, upon activation, induce caspase- 1 mediated processing of interleukin (IL) -1-cytokine members IL-1 $\beta$ and IL-18, as well as initiation of gasdermin D-dependent pyroptosis. Inflammasome activation leads to a pro-inflammatory microenvironment in the bone marrow, which drives proliferation and may induce clonal selection of mutated HSPCs. However, there are also contradictory data showing that inflammasome activation actually counteracts leukemogenesis. Overall, the beneficial or detrimental effect of inflammasome activation seems to be highly dependent on mutational, environmental, and immunological contexts and an improved understanding is fundamental to advance specific therapeutic targeting strategies. This review summarizes current knowledge about this dichotomous effect of inflammasome activation in myeloid malignancies and provides further perspectives on therapeutic targeting.

Keywords: NLRP3 inflammasome, myeloid malignancies, myelodysplastic syndromes, myeloproliferative neoplasms, chronic myeloid leukemia, acute myeloid leukemia and targeting inflammasomes

\section{INTRODUCTION}

Inflammation is the evolutionary conserved response to pathogens or injury. Although it is beneficial to fight against infection and wound healing, undesired chronic inflammation is linked to several noncommunicable disorders including diabetes, cardiovascular diseases, and cancer (Coussens and Werb, 2002; Furman et al., 2019). It is very well accepted that inflammation predisposes to growth of solid tumors, which represents one of the hallmarks of cancer (Colotta et al., 2009). More recently, the role of inflammation in hematological malignancies has gained momentum (Gañán-Gómez et al., 2015; Monlish et al., 2016; Craver et al., 2018; Sallman and List, 2019; Ratajczak et al., 2020). Myeloid malignancies, including myelodysplastic syndromes (MDS), myeloproliferative neoplasms (MPN) and acute myeloid leukemia (AML), are heterogeneous disorders originating from mutated hematopoietic stem and progenitor cells (HSPCs). Genetically, they are very heterogeneous and characterized by uncontrolled proliferation and/or blockage of differentiation in the bone-marrow (BM) of abnormal HSPCs (Corey et al., 2007; Döhner et al., 2015; Tefferi and Pardanani, 2015). With the expression of pattern recognition receptors (PRRs) and cytokine receptors, HSPCs can directly 
sense pathogen-associated molecular patterns (PAMPs) and damage-associated molecular patterns (DAMPs). These mechanisms are part of innate immunity, allow activation of pro-inflammatory cytokines to increase defense against emerging danger, and the signals eventually affect the fate choice of HSPCs as well as differentiation (King and Goodell, 2011). Recently, several studies suggested a causative role of the innate immune system mediated inflammation in the pathogenesis and progression of myeloid malignancies. Multiple key regulators of innate immunity such as toll-like receptors (TLRs) and their downstream signaling molecules, TNFR1, TNFR2 and CD95 are overexpressed or constitutively activated in HSPCs (Gañán-Gómez et al., 2015; Barreyro et al., 2018; Camacho et al., 2021). Dysregulation of these molecules leads to abnormal hematopoiesis, unbalanced cell death and proliferation in patients' BM, implying an important role in the pathogenesis of myeloid malignancies. Inflammasomes are central mediators of inflammation and growing evidence suggest their involvement in cancer progression (Karki and Kanneganti, 2019). On the contrary, few studies also suggest a beneficial role for inflammasomes in cancer (Kolb et al., 2014; Hamarsheh and Zeiser, 2020). In this review, we summarize current knowledge about this dichotomous effect of inflammasome activation in myeloid malignancies and provide further perspectives on therapeutic targeting.

\section{BIOLOGY OF INFLAMMASOMES}

\section{Pattern Recognition Receptors}

The innate immune system engages an array of germline encoded PRRs to detect the presence of microorganisms or tissue damage. PRRs recognize structures conserved among microbial species or endogenous molecules released from tissue damage and cell death, which are called PAMPs and DAMPs, respectively. Currently, there are four different classes of PRR families that includes transmembrane proteins such as the Toll-like receptors (TLRs) and C-type lectin receptors (CLRs), as well as cytoplasmic proteins such as the Retinoic acid-inducible gene (RIG)-I-like receptors (RLRs) and Nucleotide-binding oligomerization domain (NOD)-like receptors (NLRs) (Takeuchi and Akira, 2010). Compared to all the other innate immune receptor molecules, the NLRs appear to be predominantly involved in chronic non-infectious sterile inflammation (Schroder and Tschopp, 2010). Among the NLR family, several NLRP (NOD, leucine rich repeat and pyrin domain containing) proteins form inflammasome complexes (Martinon et al., 2009).

\section{Different Types of Inflammasomes}

Inflammasomes are multiprotein complexes that activate inflammatory caspases such as Caspase-1. They process the precursor molecules of IL-1 cytokine members IL- $1 \beta$ and IL18 and induce a Gasdermin D (GSDMD)-dependent lytic form of cell death called pyroptosis (Broz and Dixit, 2016). Several NODlike receptors (NLRs), as well as HIN200 proteins, can form inflammasome complexes, namely: NLRP3, NLRP1, NLRP6, NLRC4, NAIP, AIM2, and Pyrin (Schroder and Tschopp,
2010; Broz and Dixit, 2016; Heilig and Broz, 2018). They are components of the innate immune system and are activated by different PAMPs and DAMPs (Broz and Dixit, 2016) (Figure 1A). Recognition of an inflammatory ligand leads to oligomerization of the sensor protein and recruitment of the adaptor protein ASC (apoptosis associated speck-like protein). ASC contains two death fold domains: one pyrin domain (PYD) and one caspase recruitment domain (CARD) (Martinon et al., 2009). ASC interacts with the upstream inflammasome sensor protein via its pyrin (PYD) domain. Moreover, with the help of its CARD domain it brings monomers of pro-caspase- 1 into close proximity, which initiates caspase- 1 self-cleavage and the formation of active caspase-1 (Broz and Dixit, 2016). Active caspase- 1 proteolytically activates pro-IL- $1 \beta$ and pro-IL-18 and induces GSDMD mediated pyroptosis (Figure 1B). The best understood inflammasome is NLRP3, which recognizes numerous exogenous and host ligands (Swanson et al., 2019).

\section{NLRP3 Inflammasome Activation}

Canonical NLRP3 inflammasome activation is a two-step mechanism (Latz et al., 2013). The first step is a priming step and involves a NF- $\kappa \mathrm{B}$-activating stimulus, such as lipopolysaccharide (LPS) binding to the toll-like receptor (TLR)-4 that induces transcription and translation of pro-IL$1 \beta$, as well as increased expression of NLRP3. In a second step, various triggers such as nigericin, monosodium urate crystals (MSU) (and others) activate NLRP3 to assemble the inflammasome and activate caspase-1 (Figure 1B). Several mechanisms have been reported to activate NLRP3, including potassium (K+) efflux (Pétrilli et al., 2007), lysosomal destabilization (Hornung et al., 2008), and mitochondrial ROS production (Zhou et al., 2010). Recently NEK7, a member of the family of mammalian NIMA-related kinases (NEK proteins) was shown to be an essential mediator of NLRP3 activation (He et al., 2016). However, to date, no master regulator has been found to connect various activators to NLRP3 inflammasome activation. In addition, NLRP3 can be activated through a non-canonical pathway that involves caspase-11. Intracellular LPS from Gramnegative bacteria can directly bind and activate caspase-11 (Figure 1B). This activation leads to pyroptosis through cleavage of GSDMD and triggers a secondary activation of the canonical NLRP3 inflammasome (Kayagaki et al., 2011; Shi et al., 2014). Recently, it has been shown that LPS alone can directly activate NLRP3 inflammasome independent of a second signal in human monocytes known as alternative inflammasome activation. This pathway is dependent on caspase-8 downstream of TLR4 and does not activate pyroptosis (Gaidt et al., 2016; Gaidt and Hornung, 2017).

\section{ROLE OF INFLAMMASOMES IN MYELOID MALIGNANCIES}

Hematopoiesis is a process that leads to the production of billions of mature and terminally differentiated peripheral blood cells every day from a few HSPCs that reside in the BM. It is a complex and tightly regulated process involving hematopoietic cytokine 


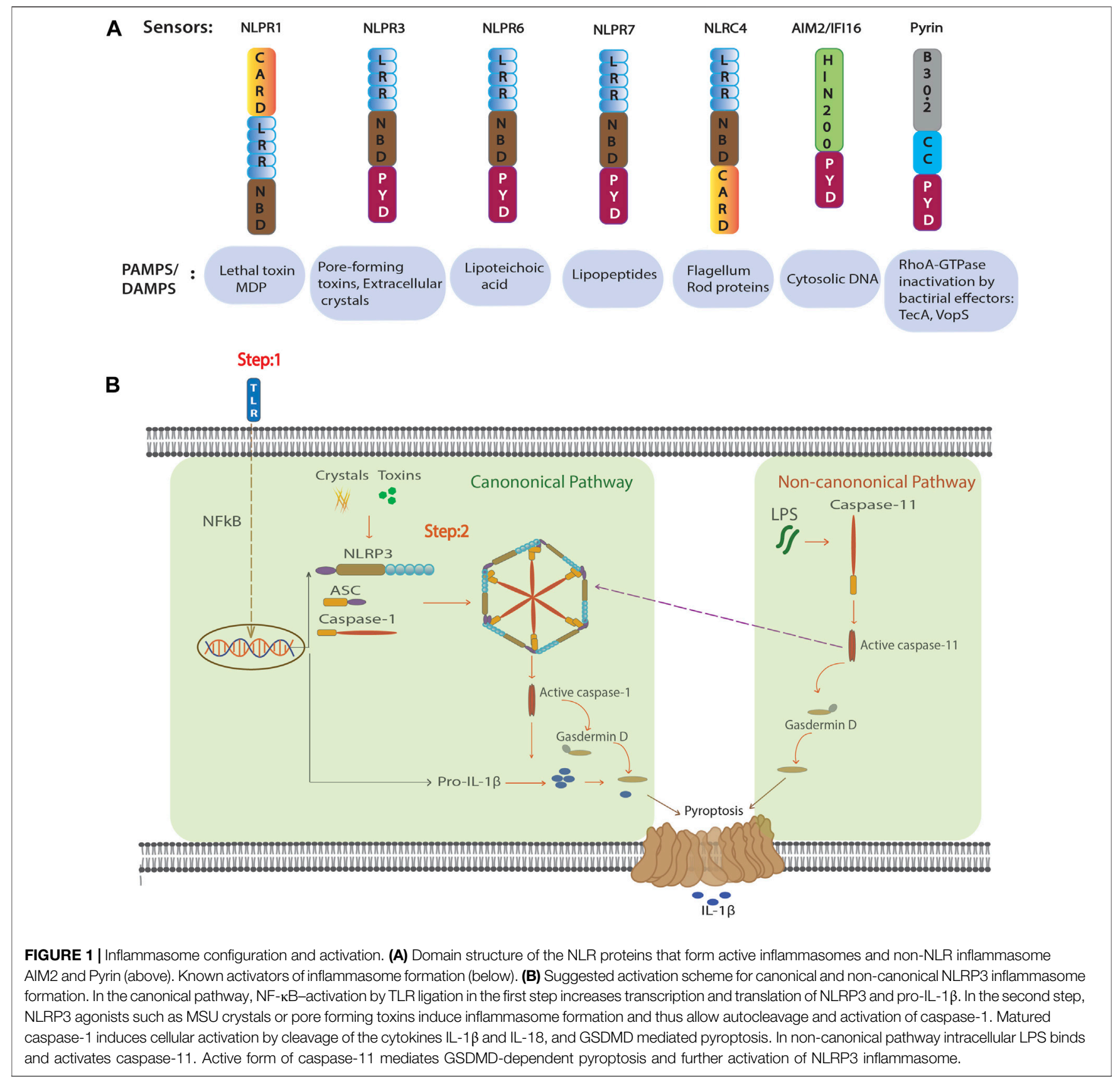

receptor signaling (Baker et al., 2007). Myeloid malignancies are clonal disorders that arise from mutated HSCs and comprised chronic disorders, such as MDS, MPN, myelodysplastic/ myeloproliferative "overlap" neoplasms (MDS/MPN), which all have the potential to transform to overt AML. Myeloid malignancies are genetically and phenotypically heterogeneous disease entities, and the prognosis is mainly determined by the inherent risk of transformation to AML (Beham-Schmid and Schmitt-Graeff, 2020). Overall, men are slightly more affected than women and the incidence rate increases with age
(Hehlmann et al., 2007; Rohrbacher and Hasford, 2009; Neukirchen et al., 2011; Juliusson et al., 2012; Moulard et al., 2014; Bonadies et al., 2017; Benzarti et al., 2019). MPN are characterized by increased production of myeloid cells, while MDS are characterized by ineffective hematopoiesis with dysplasia and cytopenia (Beham-Schmid and Schmitt-Graeff, 2020). MDS/MPN neoplasms share features of both MDS and MPN, where chronic myelomonocytic leukemia (CMML) is the most frequent entity of these overlap syndromes. CMML is characterized by myelomonocytic proliferation with persistent 
monocytosis, myeloid dysplasia and ineffective hematopoiesis leading to cytopenias (Beham-Schmid and Schmitt-Graeff, 2020). AML is a biologically heterogeneous disease characterized by a more aggressive course of the disease with increased production of mainly very immature cells called "blasts" (Beham-Schmid and Schmitt-Graeff, 2020). In all these myeloid malignancies, the myeloid compartment, in which the inflammasomes play an essential role, is severely affected, with an important impact on the regulation of inflammasome activation.

\section{Involvement of Inflammasome Mediated Pyroptosis in MDS}

Several clinical and molecular studies suggested that abnormal activation of innate immune signals and associated inflammation contribute to the pathogenesis of MDS. Abnormal levels of cytokines (e.g., TNF, IL-6, IL-8), chemokines (e.g. CXCL5, CCL3, CCL2) and growth factors (e.g., GM-CSF, VEGF, $\mathrm{M}$-CSF) in the peripheral blood and bone marrow of patients with MDS have been observed, and increased levels of these cytokines can affect the clinical outcomes of patients (GañánGómez et al., 2015). Furthermore, larger-scale epidemiological studies have demonstrated that patients with autoimmune disorders have an increased risk of developing MDS (Dalamaga et al., 2002; Anderson et al., 2009). Moreover, about $20-30 \%$ of MDS and MDS/MPN patients present with a variety of systemic autoimmune and autoinflammatory manifestations and it remains to be elucidated, if they are causative involved in the pathogenesis or just "innocent" consequences because of a deregulated immune system (Kipfer et al., 2018). Increased intramedullary cell death has been reported to be one of the main causes of the cytopenias that characterize MDS (Gañán-Gómez et al., 2015). However, the key inflammatory mediators responsible for innate immune activation and cell death remain unknown. Interestingly, few studies have reported that caspase- 1 is activated in bone marrow cells from MDS patients (Mundle et al., 1996; Boudard et al., 2000), suggesting an involvement of inflammasome activation. In line with this, Basiorka et al. reported involvement of NLRP3 inflammasome in MDS (Basiorka et al., 2016). The DAMP proteins S100A8 and S100A9 are the key mediators for activation of NLRP3 inflammasome (Simard et al., 2013). The same group showed that S100A9 is particularly overexpressed in MDS HSPCs, and it induces increased ROS production. This ultimately leads to activation of NLRP3 inflammasome, cation influx, cell swelling, and beta-catenin activation. Inhibition of NLRP3 with the icariin derivative ICTA rescued the MDS phenotype in S100A9 transgenic (S100A9 ${ }^{\mathrm{Tg}}$ ) mice (Basiorka et al., 2016). Although this study establishes the NLRP3 inflammasome as a central player in the pathology of MDS, further research is needed to confirm the precise in vivo role of the NLRP3 inflammasome in the development and progression of MDS. For example, ICTA is not a specific NLRP3 inflammasome inhibitor and has anti-inflammatory and antitumor effects and also modulates myeloid-derived suppressor cells (MDSCs) (Zhou et al., 2011). Furthermore, only $20 \%$ of S100A $9^{\mathrm{Tg}}$ transgenic mice showed an MDS-like phenotype after 9-12 months of age, suggesting additional contributing cofactors that play a role in MDS development in this mouse model (Chen et al., 2013) (personal communication with the Sheng Wei group and our own observations). Additional studies with NLRP3 specific inhibitors or using NLRP3 knockout mice in MDS mouse models such as SRSF2 (Kim et al., 2015) and SFB1 (Obeng et al., 2016) will clarify the role of NLRP3 in MDS.

It is apparent that pyroptosis plays a critical role in MDS pathology (Sallman and List, 2019). In addition to NLRP3 inflammasome, other inflammasomes and inflammasomeindependent pathways can also induce pyroptosis (Man et al., 2017; Yu et al., 2021) and may be involved in MDS. For example, NLRP1a inflammasome is highly expressed in HSPCs and over activation leads to pyroptosis of HSPCs resulting in leukopenia, bone marrow hypoplasia, and immunosuppression (Masters et al., 2012). Furthermore, the death receptor Fas and its specific ligand (Fas-L), is overexpressed and correlates with the rate of apoptosis in MDS (Bouscary et al., 1997; Gersuk et al., 1998; Gupta et al., 1999), induces inflammasome independent non-canonical IL-1 $\beta$ and IL-18 maturation and cell death via caspase- 8 (Bossaller et al., 2012). Recently, caspase- 8 has been shown to cleave GSDMD and activate pyroptosis (Sarhan et al., 2018). Collectively, these studies suggest that in addition to the NLRP3 inflammasome, other inflammasomes as well as inflammasome independent pathways could play a role in the pathology of MDS. Further detailed molecular and genetic studies are necessary to understand the role of inflammasome activation in MDS and to identify which inflammasome signaling plays a role upstream of caspase- 1 activation and at which state of the disease.

\section{Inflammasomes in MPN}

Classical MPNs comprise polycythemia vera (PV), essential thrombocythemia (ET), primary myelofibrosis (PMF), and prefibrotic PMF (Swerdlow et al., 2017). The most frequent molecular alteration that can be found in these entities is a point mutation in exon 14 of the janus kinase 2 (JAK2) gene $\left(J A K 2^{V 617 F}\right.$ ) (Baxter et al., 2005; James et al., 2005; Kralovics et al., 2005; Levine et al., 2005). While PV is almost exclusively based on a JAK2 driver mutation, ET and PMF also show mutations of calreticulin $(C A L R)$ and of the thrombopoietin receptor gene (MPL), with some triple-negative cases (Swerdlow et al., 2017). Cell intrinsic genetic alterations in HSPCs play a pivotal role in the pathogenesis of myeloid malignancies. However, the interaction between the malignant cell and niche of the HSPCs is also crucial (Korn and Méndez-Ferrer, 2017). Niches are local microenvironments that maintain and regulate stem cell biology (Morrison and Scadden, 2014). An intact, physiologic stem cell niche can inhibit proliferation of malignant HSPC (Arranz et al., 2014). On the other hand, a malignant cell can remodel the niche for its own benefit and for the disadvantage of normal HSPCs (Asada et al., 2017). Interestingly, the pro-inflammatory cytokine IL- $1 \beta$ is involved in the remodeling of the niche and is also reported to be involved in the pathogenesis of several classical MPNs, such as polycythemia vera, essential thrombocythemia, and primary myelofibrosis (Arranz et al., 2014; Asada et al., 2017; 
de Mooij et al., 2017). In line with this, a recent study showed that IL- $1 \beta$ supports clonal expansion of Jak2 mutated HSPCs in MPN mice and deletion of IL-1 $\beta$ in these mice reduces disease burden (Rai et al., 2019). Interestingly, increased expression of the AIM2 inflammasome has been reported in Jak2 mutant cells (Liew et al., 2016). Furthermore, Fidler et al. showed that Jak2 $2^{V 617 F}$ macrophages express an increase in AIM2 inflammasome activation and deletion of the AIM2 but not NLRP3 gene rescued the atherosclerosis phenotype driven by Jak2 $2^{\text {V617F }}$ clonal hematopoiesis (Fidler et al., 2021). However, it needs to be further evaluated whether AIM2 is involved in the Jak2 $2^{V 617 F}$ driven MPN phenotype.

\section{Inflammasomes in CML}

In chronic myeloid leukemia (CML), the genetic basis is a translocation that juxtaposes the abelson tyrsoin kinase gene (ABL1) from chromosome 9 to the breakpoint cluster region $(B C R)$ on chromosome 22 . The resulting fusion gene $B C R-A B L 1$ gives rise to the $\mathrm{BCR}-\mathrm{ABL}$ fusion protein and is disease defining for CML with proliferative and survival advantage of the cell (Quintás-Cardama and Cortes, 2009). Before the development of highly specific tyrosine kinase inhibitors (TKI) against BCR-ABL, CML was a life-threatening disease and can today be controlled with a life expectancy close to normal. However, leukemic stem cells (LSC) in CML are not dependent on BCR-ABL activity and persist despite TKI therapy. Therefore, more relevant targets for these LSCs are being investigated. Interestingly, CML leukemic stem cells (LSC) show increased expression of IL-1R1 and its coreceptor IL1RAP (Zhang et al., 2016; Ågerstam et al., 2016). Activation of the IL-1 $\beta /$ IL-1R1 signaling pathway increases proliferation of CML LSC and antibodies against IL1RAP suppress IL-1 $\beta$ induced proliferation. Furthermore, in CML mouse models, inhibition of the IL-1 $\beta / I L-1 R 1$ signaling pathway increases the effect of TKIs.

\section{Inflammasome Activation in MDS/MPN Overlap Syndromes}

A recent study by Hamarsheh et al. showed involvement of NLRP3 inflammasome in ras $^{G 12 D}$ mutation driven myeloid leukemia (Hamarsheh et al., 2020). They demonstrate that the $\mathrm{Kras}^{G 12 D}$ mutation in HSPCs developed a myeloproliferative and myelodysplastic phenotype, reminiscent of CMML, and mice lacking the Nlrp3 gene in Kras ${ }^{G 12 D}$ mice reversed this phenotype. Additionally, treatment with either IL-1 receptor blockade or NLRP3 inhibitor (MCC950) reduced myeloproliferation. Supporting this, they found increased caspase- 1 activation and IL- $1 \beta$ production in CMML, juvenile myelomonocytic leukemia (JMML) and AML patients with KRAS mutations as compared to patients without KRAS mutations (Hamarsheh et al., 2020). However, non-KRAS mutant cells showed caspase-1 activation and IL-1 $\beta$ production, albeit at lower levels as compared to KRAS mutant cells (Hamarsheh et al., 2020). Further studies are needed to evaluate which inflammasome is responsible for caspase- 1 activation in non-KRAS mutant leukaemia patients.

\section{Role of Inflammasome Mediated IL-1 $\beta$ in AML}

Similarly to MPN, IL-1 $\beta$ promotes the growth of malignant HSPCs in AML and inhibits normal HSPCs by altering the bone marrow niche (Carey et al., 2017; Wang et al., 2020). Furthermore, AML LSCs also showed increased expression of IL-1R1 and its co-receptor IL1RAP (Askmyr et al., 2013). Activation of the IL-1 $\beta /$ IL-1R1 signaling pathway increased AML LSC proliferation and antibodies against IL1RAP suppressed IL-1 $\beta$ induced proliferation (Askmyr et al., 2013; Ågerstam et al., 2015). There is, however, also evidence that inflammasome activation counteracts leukemogenesis. The presence of FMS-like tyrosine kinase 3 (FLT3) mutations and especially FLT3-internal tandem duplications (FLT3-ITD) are associated with poor prognosis in AML and contribute to proliferation of the malignant clone (Chu et al., 2012; Mead et al., 2013). In a FLT3-ITD AML mouse model, receptor-interacting protein kinase 3 (RIP3K) restricts myeloproliferation via inflammasome mediated IL- $1 \beta$ secretion (Höckendorf et al., 2016). Similar findings for RIP3K were observed with the oncogenic fusion protein AML1-ETO but not for MLL-ENLinduced leukemia (Höckendorf et al., 2016), suggesting that RIP3K- mediated inflammasome activation and IL- $1 \beta$ secretion play a counteracting role in some but not all AML subtypes. In addition, many drugs that are used for cancer treatment also induce IL-1 $\beta$ production through inflammasome activation (Bent et al., 2018). For example, cytarabine used to treat AML (Löwenberg et al., 2011) induces IL-1 $\beta$ secretion through NLRP3 (Wong et al., 2014). Collectively, these data suggest that the effect of inflammasome mediated IL- $1 \beta$ secretion on leukemogenesis depends on the mutational context and can either favor or counteract leukemia.

\section{Role of Inflammasome Independent IL-1 $\beta$ Secretion in Myeloid Malignancies}

As mentioned above, IL- $1 \beta$ plays a crucial role in a variety of myeloid malignancies (Arranz et al., 2017). Although, mainly inflammatory caspases from inflammasomes cleave pro-IL-1 $\beta$ into its active form IL- $1 \beta$, there is evidence that pro-IL- $1 \beta$ can be processed by inflammasome-independent mechanisms (Netea et al., 2014). Proteases, such as proteinase 3 (PR3), elastase, cathepsin G, chymase, and chymotrypsin, are expressed by neutrophils and macrophages and cleave pro-IL-1 $\beta$ (Netea et al., 2014). In addition, also metalloproteinases, such as meprins cleave pro-IL-1 $\beta$ (Broder and Becker-Pauly, 2013). Interestingly, some of these proteins are highly expressed in myeloid malignancies. For example, cathepsin G is highly expressed in AML blasts and was proposed as a therapeutic target (Alatrash et al., 2017). Furthermore, neutrophil elastase is also increased in the serum of patients with AML (Sergeeva et al., 2006). Whether these proteases significantly contribute to pro-IL-1 $\beta$ processing in myeloid malignancies is currently unknown. 


\section{TARGETING INFLAMMASOMES TO TREAT MYELOID MALIGNANCIES}

As inflammasomes are involved in myeloid malignancies, they represent attractive candidates for drug targeting. Indeed, several NLRP3 inhibitors have been developed and some are in clinical trials to treat inflammatory disorders and cancer (Mangan et al., 2018; Sallman and List, 2019; Hamarsheh and Zeiser, 2020). For example, the bruton tyrosine kinease (BTK) inhibitor ibrutinib binds directly to ASC and NLRP3, and inhibits the activation of inflammasome (Weber, 2021). This compound is currently in phase I clinical trials for high-risk MDS (Sallman and List, 2019). Further, MCC950 is a specific NLRP3 inhibitor and represents a promising molecule to target NLRP3 mediated disease progression in myeloid malignancies (Coll et al., 2015). In addition to NLRP3 inhibitors, targeting IL- $1 \beta$ is more advanced in clinical trials. There are currently three proteins approved for inflammatory diseases targeting IL-1 signaling and are under investigation for MDS treatment (Sallman and List, 2019). These are i) rilonacept, a soluble decoy receptor that binds both IL-1 $\beta$ and IL-1 $\alpha$, ii) anakinra, an antagonist of the IL-1 receptor, and iii) canakinumab, an IL-1 $\beta$ neutralizing antibody (Mangan et al., 2018). However, targeting IL-1 signaling alone will not inhibit other pro-inflammatory consequences of inflammasome activation, such as IL-18 and HMGB1 production and pyroptosis. Especially in MDS, where pyroptosis might be responsible for ineffective hematopoiesis and cytopenia, inflammasome targeting up-stream of IL- $1 \beta$, at the level of caspase-1 or higher, could have an additional beneficial effect compared to targeting IL-1 $\beta$ alone. However, in AML, inflammasome-mediated pyroptosis eliminates malignant clones (Höckendorf et al., 2016) and inhibition of inflammasome-mediated pyroptosis could, therefore, potentially also increase disease burden (Höckendorf et al., 2016). In summary, targeting components of the inflammasome to treat

\section{REFERENCES}

Ågerstam, H., Hansen, N., von Palffy, S., Sandén, C., Reckzeh, K., Karlsson, C., et al. (2016). IL1RAP Antibodies Block IL-1-induced Expansion of Candidate CML Stem Cells and Mediate Cell Killing in Xenograft Models. Blood 128, 2683-2693. doi:10.1182/blood-2015-11-679985

Ågerstam, H., Karlsson, C., Hansen, N., Sandén, C., Askmyr, M., von Palffy, S., et al. (2015). Antibodies Targeting Human IL1RAP (IL1R3) Show Therapeutic Effects in Xenograft Models of Acute Myeloid Leukemia. Proc. Natl. Acad. Sci. USA 112, 10786-10791. doi:10.1073/pnas.1422749112

Alatrash, G., Garber, H. R., Zhang, M., Sukhumalchandra, P., Qiu, Y., Jakher, H., et al. (2017). Cathepsin G Is Broadly Expressed in Acute Myeloid Leukemia and Is an Effective Immunotherapeutic Target. Leukemia 31, 234-237. doi:10.1038/ leu.2016.249

Anderson, L. A., Pfeiffer, R. M., Landgren, O., Gadalla, S., Berndt, S. I., and Engels, E. A. (2009). Risks of Myeloid Malignancies in Patients with Autoimmune Conditions. Br. J. Cancer 100, 822-828. doi:10.1038/sj.bjc.6604935

Arranz, L., Arrierodel, M. D. M. M., and Villatoro, A. (2017). Interleukin-1 $\beta$ as Emerging Therapeutic Target in Hematological Malignancies and Potentially in Their Complications. Blood Rev. 31, 306-317. doi:10.1016/j.blre.2017.05.001

Arranz, L., Sánchez-Aguilera, A., Martín-Pérez, D., Isern, J., Langa, X., Tzankov, A., et al. (2014). Neuropathy of Haematopoietic Stem Cell Niche Is Essential for Myeloproliferative Neoplasms. Nature 512, 78-81. doi:10.1038/nature13383 myeloid malignancies could be an interesting additive to existing therapies. However, due to its dichotomous role in myeloid malignancies, more knowledge about the mechanisms is indispensable to understand in which context inflammasome targeting might be beneficial or deleterious.

\section{CONCLUSION}

There has been enormous progress for the past decade in understanding the molecular mechanisms of inflammasome activation and its role in myeloid malignancies. However, more efforts are needed to understand comprehensively the context-dependent and dichotomous role of inflammasomes in myeloid malignancies. Since myeloid malignancies are genetically heterogeneous and various genetic mutations seem to converge in inflammasome activation, modulating inflammasome activity could provide a targeted approach to a specific pathway with a larger impact on HSCs with different mutations.

\section{AUTHOR CONTRIBUTIONS}

All authors listed have made a substantial, direct, and intellectual contribution to the work and approved it for publication.

\section{FUNDING}

This work was supported by the Swiss National Science Foundation (PP00P3_157486, PP00P3_183721 and PP00P3_190073) (RA), Novartis Stiftung für medizinisch-biologische Forschung (RA), Olga Mayenfisch Stiftung and Swiss Cancer Research grants RA and NA (KFS-4896) and NB (KFS-5230).

Asada, N., Takeishi, S., and Frenette, P. S. (2017). Complexity of Bone Marrow Hematopoietic Stem Cell Niche. Int. J. Hematol. 106, 45-54. doi:10.1007/ s12185-017-2262-9

Askmyr, M., Ågerstam, H., Hansen, N., Gordon, S., Arvanitakis, A., Rissler, M., et al. (2013). Selective Killing of Candidate AML Stem Cells by Antibody Targeting of IL1RAP. Blood 121, 3709-3713. doi:10.1182/blood-2012-09-458935

Baker, S. J., Rane, S. G., and Reddy, E. P. (2007). Hematopoietic Cytokine Receptor Signaling. Oncogene 26, 6724-6737. doi:10.1038/sj.onc.1210757

Barreyro, L., Chlon, T. M., and Starczynowski, D. T. (2018). Chronic Immune Response Dysregulation in MDS Pathogenesis. Blood 132, 1553-1560. doi:10.1182/blood-2018-03-784116

Basiorka, A. A., McGraw, K. L., Eksioglu, E. A., Chen, X., Johnson, J., Zhang, L., et al. (2016). The NLRP3 Inflammasome Functions as a Driver of the Myelodysplastic Syndrome Phenotype. Blood 128, 2960-2975. doi:10.1182/ blood-2016-07-730556

Baxter, E. J., Scott, L. M., Campbell, P. J., East, C., Fourouclas, N., Swanton, S., et al. (2005). Acquired Mutation of the Tyrosine Kinase JAK2 in Human Myeloproliferative Disorders. The Lancet 365, 1054-1061. doi:10.1016/ s0140-6736(05)71142-9

Beham-Schmid, C., and Schmitt-Graeff, A. (2020). Bone Marrow Biopsy Pathology, A Practical Guide. Berlin/Heidelberg, Germany: Springer. Essentials Diagnostic Pathology, 383-533. doi:10.1007/978-3-662-60309-3_13

Bent, R., Moll, L., Grabbe, S., and Bros, M. (2018). Interleukin-1 Beta-A Friend or Foe in Malignancies? Int. J. Mol. Sci. 19, 2155. doi:10.3390/ijms19082155 
Benzarti, S., Daskalakis, M., Feller, A., Bacher, V. U., Schnegg-Kaufmann, A., Rüfer, A., et al. (2019). Trends of Incidence and Survival of Patients with Chronic Myelomonocytic Leukemia between 1999 and 2014: A Comparison between Swiss and American Population-Based Cancer Registries. Cancer Epidemiol. 59, 51-57. doi:10.1016/j.canep.2019.01.003

Bonadies, N., Feller, A., Rovo, A., Ruefer, A., Blum, S., Gerber, B., et al. (2017). Trends of Classification, Incidence, Mortality, and Survival of MDS Patients in Switzerland between 2001 and 2012. Cancer Epidemiol. 46, 85-92. doi:10.1016/ j.canep.2016.12.005

Bossaller, L., Chiang, P.-I., Schmidt-Lauber, C., Ganesan, S., Kaiser, W. J., Rathinam, V. A. K., et al. (2012). Cutting Edge: FAS (CD95) Mediates Noncanonical IL-1 $\beta$ and IL-18 Maturation via Caspase-8 in an RIP3independent Manner. J. Immunol. 189, 5508-5512. doi:10.4049/ jimmunol.1202121

Boudard, D., Sordet, O., Vasselon, C., Revol, V., Berthéas, M.-F., Freyssenet, D., et al. (2000). Expression and Activity of Caspases 1 and 3 in Myelodysplastic Syndromes. Leukemia 14, 2045-2051. doi:10.1038/sj.leu.2401959

Bouscary, D., De Vos, J., Guesnu, M., Jondeau, K., Viguier, F., Melle, J., et al. (1997). Fas/Apo-1(CD95) Expression and Apoptosis in Patients with Myelodysplastic Syndromes. Leukemia 11, 839-845. doi:10.1038/sj.leu.2400654

Broder, C., and Becker-Pauly, C. (2013). The Metalloproteases Meprin $\alpha$ and Meprin $\beta$ : Unique Enzymes in Inflammation, Neurodegeneration, Cancer and Fibrosis. Biochem. J. 450, 253-264. doi:10.1042/bj20121751

Broz, P., and Dixit, V. M. (2016). Inflammasomes: Mechanism of Assembly, Regulation and Signalling. Nat. Rev. Immunol. 16, 407-420. doi:10.1038/ nri.2016.58

Camacho, V., Kuznetsova, V., and Welner, R. S. (2021). Inflammatory Cytokines Shape an Altered Immune Response during Myeloid Malignancies. Front. Immunol. 12, 772408. doi:10.3389/fimmu.2021.772408

Carey, A., Edwards, D. K., Eide, C. A., Newell, L., Traer, E., Medeiros, B. C., et al. (2017). Identification of Interleukin-1 by Functional Screening as a Key Mediator of Cellular Expansion and Disease Progression in Acute Myeloid Leukemia. Cel Rep. 18, 3204-3218. doi:10.1016/ j.celrep.2017.03.018

Chen, X., Eksioglu, E. A., Zhou, J., Zhang, L., Djeu, J., Fortenbery, N., et al. (2013). Induction of Myelodysplasia by Myeloid-Derived Suppressor Cells. J. Clin. Invest. 123, 4595-4611. doi:10.1172/jci67580

Chu, S. H., Heiser, D., Li, L., Kaplan, I., Collector, M., Huso, D., et al. (2012). FLT3ITD Knockin Impairs Hematopoietic Stem Cell Quiescence/Homeostasis, Leading to Myeloproliferative Neoplasm. Cell Stem Cell 11, 346-358. doi:10.1016/j.stem.2012.05.027

Coll, R. C., Robertson, A. A. B., Chae, J. J., Higgins, S. C., Muñoz-Planillo, R., Inserra, M. C., et al. (2015). A Small-Molecule Inhibitor of the NLRP3 Inflammasome for the Treatment of Inflammatory Diseases. Nat. Med. 21, 248-255. doi:10.1038/nm.3806

Colotta, F., Allavena, P., Sica, A., Garlanda, C., and Mantovani, A. (2009). Cancerrelated Inflammation, the Seventh Hallmark of Cancer: Links to Genetic Instability. Carcinogenesis 30, 1073-1081. doi:10.1093/carcin/bgp127

Corey, S. J., Minden, M. D., Barber, D. L., Kantarjian, H., Wang, J. C. Y., and Schimmer, A. D. (2007). Myelodysplastic Syndromes: the Complexity of StemCell Diseases. Nat. Rev. Cancer 7, 118-129. doi:10.1038/nrc2047

Coussens, L. M., and Werb, Z. (2002). Inflammation and Cancer. Nature 420, 860-867. doi:10.1038/nature01322

Craver, B., El Alaoui, K., Scherber, R., and Fleischman, A. (2018). The Critical Role of Inflammation in the Pathogenesis and Progression of Myeloid Malignancies. Cancers 10, 104. doi:10.3390/cancers10040104

Dalamaga, M., Petridou, E., Cook, F. E., and Trichopoulos, D. (2002). Risk Factors for Myelodysplastic Syndromes: a Case-Control Study in Greece. Cancer Causes Control 13, 603-608. doi:10.1023/a:1019573319803

de Mooij, C. E. M., Netea, M. G., van der Velden, W. J. F. M., and Blijlevens, N. M. A. (2017). Targeting the Interleukin-1 Pathway in Patients with Hematological Disorders. Blood 129, 3155-3164. doi:10.1182/blood-2016-12-754994

Döhner, H., Weisdorf, D. J., and Bloomfield, C. D. (2015). Acute Myeloid Leukemia. N. Engl. J. Med. 373, 1136-1152. doi:10.1056/nejmra1406184

Fidler, T. P., Xue, C., Yalcinkaya, M., Hardaway, B., Abramowicz, S., Xiao, T., et al. (2021). The AIM2 Inflammasome Exacerbates Atherosclerosis in Clonal Haematopoiesis. Nature 592, 296-301. doi:10.1038/s41586-021-03341-5
Furman, D., Campisi, J., Verdin, E., Carrera-Bastos, P., Targ, S., Franceschi, C., et al. (2019). Chronic Inflammation in the Etiology of Disease across the Life Span. Nat. Med. 25, 1822-1832. doi:10.1038/s41591-019-0675-0

Gaidt, M. M., Ebert, T. S., Chauhan, D., Schmidt, T., Schmid-Burgk, J. L., Rapino, F., et al. (2016). Human Monocytes Engage an Alternative Inflammasome Pathway. Immunity 44, 833-846. doi:10.1016/j.immuni.2016.01.012

Gaidt, M. M., and Hornung, V. (2017). Alternative Inflammasome Activation Enables IL-1 $\beta$ Release from Living Cells. Curr. Opin. Immunol. 44, 7-13. doi:10.1016/j.coi.2016.10.007

Gañán-Gómez, I., Wei, Y., Starczynowski, D. T., Colla, S., Yang, H., Cabrero-Calvo, M., et al. (2015). Deregulation of Innate Immune and Inflammatory Signaling in Myelodysplastic Syndromes. Leukemia 29, 1458-1469. doi:10.1038/ leu.2015.69

Gersuk, G. M., Beckham, C., Loken, M. R., Kiener, P., Anderson, J. E., Farrand, A., et al. (1998). A Role for Tumour Necrosis Factor- $\alpha$, Fas and Fas-Ligand in Marrow Failure Associated with Myelodysplastic Syndrome. Br. J. Haematol. 103, 176-188. doi:10.1046/j.1365-2141.1998.00933.x

Gupta, P., Niehans, G., LeRoy, S., Gupta, K., Morrison, V., Schultz, C., et al. (1999). Fas Ligand Expression in the Bone Marrow in Myelodysplastic Syndromes Correlates with FAB Subtype and Anemia, and Predicts Survival. Leukemia 13, 44-53. doi:10.1038/sj.leu.2401233

Hamarsheh, S. a., Osswald, L., Saller, B. S., Unger, S., De Feo, D., Vinnakota, J. M., et al. (2020). Oncogenic KrasG12D Causes Myeloproliferation via NLRP3 Inflammasome Activation. Nat. Commun. 11, 1659. doi:10.1038/s41467-02015497-1

Hamarsheh, S. a., and Zeiser, R. (2020). NLRP3 Inflammasome Activation in Cancer: A Double-Edged Sword. Front. Immunol. 11, 1444. doi:10.3389/ fimmu.2020.01444

He, Y., Zeng, M. Y., Yang, D., Motro, B., and Núñez, G. (2016). NEK7 Is an Essential Mediator of NLRP3 Activation Downstream of Potassium Efflux. Nature 530, 354-357. doi:10.1038/nature16959

Hehlmann, R., Hochhaus, A., and Baccarani, M. (2007). LeukemiaNet, on Behalf of the EChronic Myeloid Leukaemia. Lancet 370, 342-350. doi:10.1016/s01406736(07)61165-9

Heilig, R., and Broz, P. (2018). Function and Mechanism of the Pyrin Inflammasome. Eur. J. Immunol. 48, 230-238. doi:10.1002/eji.201746947

Höckendorf, U., Yabal, M., Herold, T., Munkhbaatar, E., Rott, S., Jilg, S., et al. (2016). RIPK3 Restricts Myeloid Leukemogenesis by Promoting Cell Death and Differentiation of Leukemia Initiating Cells. Cancer Cell 30, 75-91. doi:10.1016/ j.ccell.2016.06.002

Hornung, V., Bauernfeind, F., Halle, A., Samstad, E. O., Kono, H., Rock, K. L., et al. (2008). Silica Crystals and Aluminum Salts Activate the NALP3 Inflammasome through Phagosomal Destabilization. Nat. Immunol. 9, 847-856. doi:10.1038/ ni. 1631

James, C., Ugo, V., Le Couédic, J.-P., Staerk, J., Delhommeau, F., Lacout, C., et al. (2005). A Unique Clonal JAK2 Mutation Leading to Constitutive Signalling Causes Polycythaemia Vera. Nature 434, 1144-1148. doi:10.1038/nature03546

Juliusson, G., Lazarevic, V., Hörstedt, A.-S., Hagberg, O., Höglund, M., and Höglund, M. (2012). Acute Myeloid Leukemia in the Real World: Why Population-Based Registries Are Needed. Blood 119, 3890-3899. doi:10.1182/blood-2011-12-379008

Karki, R., and Kanneganti, T.-D. (2019). Diverging Inflammasome Signals in Tumorigenesis and Potential Targeting. Nat. Rev. Cancer 19, 197-214. doi:10.1038/s41568-019-0123-y

Kayagaki, N., Warming, S., Lamkanfi, M., Walle, L. V., Louie, S., Dong, J., et al. (2011). Non-canonical Inflammasome Activation Targets Caspase-11. Nature 479, 117-121. doi:10.1038/nature10558

Kim, E., Ilagan, J. O., Liang, Y., Daubner, G. M., Lee, S. C.-W., Ramakrishnan, A., et al. (2015). SRSF2 Mutations Contribute to Myelodysplasia by Mutantspecific Effects on Exon Recognition. Cancer Cell 27, 617-630. doi:10.1016/ j.ccell.2015.04.006

King, K. Y., and Goodell, M. A. (2011). Inflammatory Modulation of HSCs: Viewing the HSC as a Foundation for the Immune Response. Nat. Rev. Immunol. 11, 685-692. doi:10.1038/nri3062

Kipfer, B., Daikeler, T., Kuchen, S., Hallal, M., Andina, N., Allam, R., et al. (2018). Increased Cardiovascular Comorbidities in Patients with Myelodysplastic Syndromes and Chronic Myelomonocytic Leukemia Presenting with 
Systemic Inflammatory and Autoimmune Manifestations. Semin. Hematol. 55, 242-247. doi:10.1053/j.seminhematol.2018.05.002

Kolb, R., Liu, G.-H., Janowski, A. M., Sutterwala, F. S., and Zhang, W. (2014). Inflammasomes in Cancer: a Double-Edged Sword. Protein Cell 5, 12-20. doi:10.1007/s13238-013-0001-4

Korn, C., and Méndez-Ferrer, S. (2017). Myeloid Malignancies and the Microenvironment. Blood 129, 811-822. doi:10.1182/blood-2016-09670224

Kralovics, R., Passamonti, F., Buser, A. S., Teo, S.-S., Tiedt, R., Passweg, J. R., et al. (2005). A Gain-Of-Function Mutation ofJAK2in Myeloproliferative Disorders. N. Engl. J. Med. 352, 1779-1790. doi:10.1056/nejmoa051113

Latz, E., Xiao, T. S., and Stutz, A. (2013). Activation and Regulation of the Inflammasomes. Nat. Rev. Immunol. 13, 397-411. doi:10.1038/nri3452

Levine, R. L., Wadleigh, M., Cools, J., Ebert, B. L., Wernig, G., Huntly, B. J. P., et al. (2005). Activating Mutation in the Tyrosine Kinase JAK2 in Polycythemia Vera, Essential Thrombocythemia, and Myeloid Metaplasia with Myelofibrosis. Cancer Cell 7, 387-397. doi:10.1016/ j.ccr.2005.03.023

Liew, E. L., Araki, M., Hironaka, Y., Mori, S., Tan, T. Z., Morishita, S., et al. (2016). Identification of AIM2 as a Downstream Target of JAK2V617F. Exp. Hematol. Oncol. 5, 2. doi:10.1186/s40164-016-0032-7

Löwenberg, B., Pabst, T., Vellenga, E., van Putten, W., Schouten, H. C., Graux, C., et al. (2011). Cytarabine Dose for Acute Myeloid Leukemia. N. Engl. J. Med. 364, 1027-1036. doi:10.1056/nejmoa1010222

Man, S. M., Karki, R., and Kanneganti, T.-D. (2017). Molecular Mechanisms and Functions of Pyroptosis, Inflammatory Caspases and Inflammasomes in Infectious Diseases. Immunol. Rev. 277, 61-75. doi:10.1111/imr.12534

Mangan, M. S. J., Olhava, E. J., Roush, W. R., Seidel, H. M., Glick, G. D., and Latz, E. (2018). Targeting the NLRP3 Inflammasome in Inflammatory Diseases. Nat. Rev. Drug Discov. 17, 588-606. doi:10.1038/nrd.2018.97

Martinon, F., Mayor, A., and Tschopp, J. (2009). The Inflammasomes: Guardians of the Body. Annu. Rev. Immunol. 27, 229-265. doi:10.1146/ annurev.immunol.021908.132715

Masters, S. L., Gerlic, M., Metcalf, D., Preston, S., Pellegrini, M., O'Donnell, J. A., et al. (2012). NLRP1 Inflammasome Activation Induces Pyroptosis of Hematopoietic Progenitor Cells. Immunity 37, 1009-1023. doi:10.1016/ j.immuni.2012.08.027

Mead, A. J., Kharazi, S., Atkinson, D., Macaulay, I., Pecquet, C., Loughran, S., et al. (2013). FLT3-ITDs Instruct a Myeloid Differentiation and Transformation Bias in Lymphomyeloid Multipotent Progenitors. Cel Rep. 3, 1766-1776. doi:10.1016/j.celrep.2013.04.031

Monlish, D. A., Bhatt, S. T., and Schuettpelz, L. G. (2016). The Role of Toll-like Receptors in Hematopoietic Malignancies. Front. Immunol. 7, 390. doi:10.3389/ fimmu.2016.00390

Morrison, S. J., and Scadden, D. T. (2014). The Bone Marrow Niche for Haematopoietic Stem Cells. Nature 505, 327-334. doi:10.1038/nature12984

Moulard, O., Mehta, J., Fryzek, J., Olivares, R., Iqbal, U., and Mesa, R. A. (2014). Epidemiology of Myelofibrosis, Essential Thrombocythemia, and Polycythemia Vera in the European Union. Eur. J. Haematol. 92, 289-297. doi:10.1111/ ejh.12256

Mundle, S., Venugopal, P., Cartlidge, J., Pandav, D., Broady-Robinson, L., Gezer, S., et al. (1996). Indication of an Involvement of Interleukin-1 Beta Converting Enzyme- like Protease in Intramedullary Apoptotic Cell Death in the Bone Marrow of Patients with Myelodysplastic Syndromes. Blood 88, 2640-2647. doi:10.1182/blood.v88.7.2640.bloodjournal8872640

Netea, M. G., van de Veerdonkvan de, F. L., van der Meer, J. W. M., Dinarello, C. A., and Joosten, L. A. B. (2015). Inflammasome-Independent Regulation of IL-1Family Cytokines. Annu. Rev. Immunol. 33, 49-77. doi:10.1146/annurevimmunol-032414-112306

Neukirchen, J., Schoonen, W. M., Strupp, C., Gattermann, N., Aul, C., Haas, R., et al. (2011). Incidence and Prevalence of Myelodysplastic Syndromes: Data from the Düsseldorf MDS-Registry. Leuk. Res. 35, 1591-1596. doi:10.1016/ j.leukres.2011.06.001

Obeng, E. A., Chappell, R. J., Seiler, M., Chen, M. C., Campagna, D. R., Schmidt, P. J., et al. (2016). Physiologic Expression of Sf3b1 K700E Causes Impaired Erythropoiesis, Aberrant Splicing, and Sensitivity to Therapeutic Spliceosome Modulation. Cancer Cell 30, 404-417. doi:10.1016/j.ccell.2016.08.006
Pétrilli, V., Papin, S., Dostert, C., Mayor, A., Martinon, F., and Tschopp, J. (2007). Activation of the NALP3 Inflammasome Is Triggered by Low Intracellular Potassium Concentration. Cell Death Differ 14, 1583-1589. doi:10.1038/ sj.cdd. 4402195

Quintás-Cardama, A., and Cortes, J. (2009). Molecular Biology of Bcr-Abl1Positive Chronic Myeloid Leukemia. Blood 113, 1619-1630. doi:10.1182/ blood-2008-03-144790

Rai, S., Hansen, N., Hao-Shen, H., Dirnhofer, S., Tata, N. R., and Skoda, R. C. (2019). IL-1 $\beta$ Secreted from Mutant Cells Carrying JAK2-V617Ffavors Early Clonal Expansion and Promotes MPN Disease Initiation and Progression. Blood 134, 307. doi:10.1182/blood-2019-129800

Ratajczak, M. Z., Bujko, K., Cymer, M., Thapa, A., Adamiak, M., Ratajczak, J., et al. (2020). The Nlrp3 Inflammasome as a "Rising star" in Studies of normal and Malignant Hematopoiesis. Leukemia 34, 1512-1523. doi:10.1038/s41375-0200827-8

Rohrbacher, M., and Hasford, J. (2009). Epidemiology of Chronic Myeloid Leukaemia (CML). Best Pract. Res. Clin. Haematol. 22, 295-302. doi:10.1016/j.beha.2009.07.007

Sallman, D. A., and List, A. (2019). The central Role of Inflammatory Signaling in the Pathogenesis of Myelodysplastic Syndromes. Blood 133, 1039-1048. doi:10.1182/blood-2018-10-844654

Sarhan, J., Liu, B. C., Muendlein, H. I., Li, P., Nilson, R., Tang, A. Y., et al. (2018). Caspase-8 Induces Cleavage of Gasdermin $\mathrm{D}$ to Elicit Pyroptosis duringYersiniainfection. Proc. Natl. Acad. Sci. USA 115, E10888-E10897. doi:10.1073/pnas.1809548115

Schroder, K., and Tschopp, J. (2010). The Inflammasomes. Cell 140, 821-832. doi:10.1016/j.cell.2010.01.040

Sergeeva, A., Ono, Y., and Molldrem, J. J. (2006). Elevated Serum Neutrophil Elastase but Not Proteinase 3 Is Present in Patients with Myeloid Leukemia. Blood 108, 4430. doi:10.1182/blood.v108.11.4430.4430

Shi, J., Zhao, Y., Wang, Y., Gao, W., Ding, J., Li, P., et al. (2014). Inflammatory Caspases Are Innate Immune Receptors for Intracellular LPS. Nature 514, 187-192. doi:10.1038/nature13683

Simard, J.-C., Cesaro, A., Chapeton-Montes, J., Tardif, M., Antoine, F., Girard, D., et al. (2013). S100A8 and S100A9 Induce Cytokine Expression and Regulate the NLRP3 Inflammasome via ROS-dependent Activation of NF-kB1. PLoS ONE 8, e72138. doi:10.1371/journal.pone.0072138

Swanson, K. V., Deng, M., and Ting, J. P.-Y. (2019). The NLRP3 Inflammasome: Molecular Activation and Regulation to Therapeutics. Nat. Rev. Immunol. 19, 477-489. doi:10.1038/s41577-019-0165-0

Swerdlow, S. H., Campo, E., Harris, N. L., Jaffe, E. S., Pileri, S. A., Stein, H., et al. (2017). WHO Classification of Tumours of Haematopoietic and Lymphoid Tissues. Lyon, France: IARC publications. Available at: https://publications. iarc.fr/Book-And-Report-Series/Who-Classification-Of-Tumours/WHOClassification-Of-Tumours-Of-Haematopoietic-And-LymphoidTissues-2017 (Accessed, 2017).

Takeuchi, O., and Akira, S. (2010). Pattern Recognition Receptors and Inflammation. Cell 140, 805-820. doi:10.1016/j.cell.2010.01.022

Tefferi, A., and Pardanani, A. (2015). Myeloproliferative Neoplasms. Jama Oncol. 1, 97-105. doi:10.1001/jamaoncol.2015.89

Wang, Y., Sun, X., Yuan, S., Hou, S., Guo, T., Chu, Y., et al. (2020). Interleukin-1 $\beta$ Inhibits normal Hematopoietic Expansion and Promotes Acute Myeloid Leukemia Progression via the Bone Marrow Niche. Cytotherapy 22, 127-134. doi:10.1016/j.jcyt.2020.01.001

Weber, A. N. R. (2021). Targeting the NLRP3 Inflammasome via BTK. Front. Cel Dev. Biol. 9, 630479. doi:10.3389/fcell.2021.630479

Wong, J., Tran, L. T., Magun, E. A., Magun, B. E., and Wood, L. J. (2014). Production of IL- $1 \beta$ by Bone Marrow-Derived Macrophages in Response to Chemotherapeutic Drugs. Cancer Biol. Ther. 15, 1395-1403. doi:10.4161/ cbt. 29922

Yu, P., Zhang, X., Liu, N., Tang, L., Peng, C., and Chen, X. (2021). Pyroptosis: Mechanisms and Diseases. Sig. Transduct. Target. Ther. 6, 128. doi:10.1038/ s41392-021-00507-5

Zhang, B., Chu, S., Agarwal, P., Campbell, V. L., Hopcroft, L., Jørgensen, H. G., et al. (2016). Inhibition of Interleukin-1 Signaling Enhances Elimination of Tyrosine Kinase Inhibitor-Treated CML Stem Cells. Blood 128, 2671-2682. doi:10.1182/blood-2015-11-679928 
Zhou, J., Wu, J., Chen, X., Fortenbery, N., Eksioglu, E., Kodumudi, K. N., et al. (2011). Icariin and its Derivative, ICT, Exert Anti-inflammatory, Anti-tumor Effects, and Modulate Myeloid Derived Suppressive Cells (MDSCs) Functions. Int. Immunopharmacol. 11, 890-898. doi:10.1016/ j.intimp.2011.01.007

Zhou, R., Yazdi, A. S., Menu, P., and Tschopp, J. (2010). A Role for Mitochondria in NLRP3 Inflammasome Activation. Nature 469, 221-225. doi:10.1038/ nature 09663

Conflict of Interest: The authors declare that the research was conducted in the absence of any commercial or financial relationships that could be construed as a potential conflict of interest.
Publisher's Note: All claims expressed in this article are solely those of the authors and do not necessarily represent those of their affiliated organizations, or those of the publisher, the editors and the reviewers. Any product that may be evaluated in this article, or claim that may be made by its manufacturer, is not guaranteed or endorsed by the publisher.

Copyright (c) 2022 Andina, Bonadies and Allam. This is an open-access article distributed under the terms of the Creative Commons Attribution License (CC BY).

The use, distribution or reproduction in other forums is permitted, provided the original author(s) and the copyright owner(s) are credited and that the original publication in this journal is cited, in accordance with accepted academic practice. No use, distribution or reproduction is permitted which does not comply with these terms. 